\title{
A study of Comparative analysis of fuzzy logic controller and neural network for dc-dc buck converter
}

\author{
Shaik Gousia begum ${ }^{1}$, and Syed Sarfaraz Nawaz ${ }^{2}$ \\ ${ }^{1}$ EEE Department, GRIET, Hyderabad \\ ${ }^{2}$ EEE Department, GRIET, Hyderabad.
}

\begin{abstract}
This paper presents the comparative analysis between fuzzy logic controller and neural network for DC-DC Buck converter. The major drawback in the conventional buck converter is when the input voltage or load change, the output voltage also changes which reduces the overall efficiency of the buck converter. So here we are using non linear controllers for buck converter which respond quickly for perturbations and maintains the fixed load voltage even when there are non-linearity's occurs compared to a linear controllers like P,PI,PID controllers which can't withstand when perturbations occur. Simplicity, low cost and adaptability to the complex systems without mathematical modeling are the best features of Fuzzy Logic controller and neural networks. The Two implementations are analyzed in detail and simulated in MATLAB/SIMULINK environment and results presented. Proposed approach is implemented on DC to DC step down converter for an input of $230 \mathrm{~V}$ and performance characteristics like maximum overshoot, settling time and efficiency of the converter are studied.
\end{abstract}

\section{Introduction}

The design of dc-dc buck converter is to maintain a constant output voltage under the different load current and unregulated input voltage. The transient overshoot and recovery time of the output voltage should be minimized for stable operation in many electronic applications, which is ensured by the controller in the closed loop [1]. Classical controllers like PWM control, proportional (P) controller, proportional integral (PI) controller, proportional integral derivative(PID) [3] controllers only provides results which is either true or false. These controllers don't provide adequate results when there is nonlinearities in parameters or load. Recently, several methods have been proposed in the literature to alleviate the deficiency of the classical linear controllers for power converters. So non-linear controllers like fuzzy logic controllers and neural network etc are most widely used.

Now a days we are facing situations where we are unable to determine whether the state is true or false. Term "fuzzy" describes something that is non-linear or indefinite. Fuzzy logic is based on the observation that people make decisions based on imprecise or non numerical information. Neural networks are the set of algorithms inspired by the functioning of the human brain.So we are using non linear controllers for controlling the non-linearity's in the load because it responds faster to a transient condition, easy to design and implementation
[4]. So here proposed controllers are used to stabilize buck converter's load voltage in transient state conditions [6].

\section{Buck converter}

The DC-DC buck converters are efficiently reduces the voltage levels as per our requirement. The basic circuit diagram of the Buck converter is shown in Fig.1. Here the MOSFET is controlled by duty cycles which are given by the non-linear controllers.

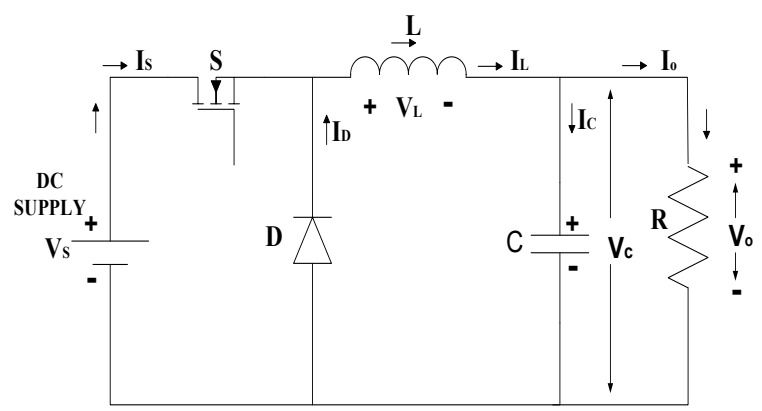

Fig 1. Circuit Diagram of DC-DC Buck Converter

Here, $\mathrm{V}_{0}$ is the output voltage, $\mathrm{V}_{\mathrm{L}}$ is the inductor current, $I_{C}$ is the capacitor current, $V_{C}$ is the voltage across the capacitor.

The modes of operation of buck converter are explained below.

Mode 1: When switch is closed, the current in the load and the charge of a capacitor is increase gradually because the energy also being stored in inductor. Throughout this 
the diode gets reverse biased because there will be a positive voltage across the cathode.

So the voltage across inductor is $V_{L}=V_{S}-V_{0}$

Mode 2: When switch is opened, the polarity of the inductor voltage changes so the diode gets forward biased but current flows in the same direction. Once the inductor returned the large part of its stored energy to the circuit, the charge stored in capacitor becomes the main source of current flowing in the circuit until the next ON period begins.

The voltage across inductor is $V_{L}=-V_{O}$

So , the output voltage is,

$$
V_{0}=D V_{S}
$$

Where, $D=T_{\mathrm{ON}} / T$

\section{Controller design}

\subsection{Fuzzy logic controller:}

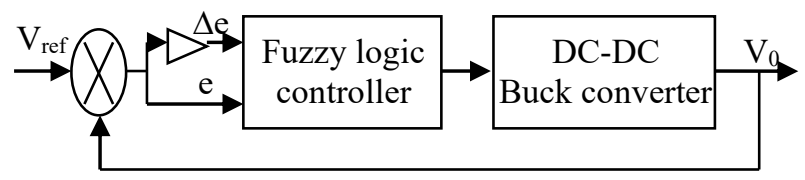

Fig.2. Block diagram of Fuzzy logic controller (FLC) for buck converter

Fig.2 shows the block diagram of the FLC for buck converter.Fuzzy logic is a mathematical logic which is based "degree of truth" unlike classical "true or false". It handles with imprecise or uncertain data. Fuzzy logic controller [8] is easy develop and design and can operate at wider operating conditions. Fuzzy logic controller is utilized in different industrial automation \& household appliances.

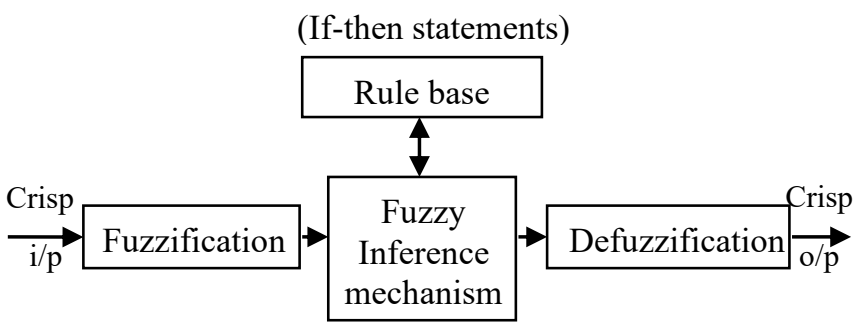

Fig.3. Fuzzy Logic Controller block diagram

Input: These are the measured plant output values.

Fuzzification: Each input data i.e., various values of error (e) and change in error $(\Delta \mathrm{e})$ is mapped to a membership value between 0 and 1 .
Rule base: Rule base is a combination of different types of rules. The rules applied in fuzzy logic algorithm are generally "if and then" statements. In this, 'if' means the condition \& 'then' means conclusion.

- If the load voltage of buck converter is more than the required voltage then duty cycle should be minimized.

- If the load voltage of buck converter is less than the Vref then the duty cycle should be increased.

Inference mechanism: In this the decision is made for different situations and generate a control signal which is given to the plant.

Defuzzification: This is opposite process of fuzzification. It aggregates all decisions (which are been taken) into a one single crisp value which is given to the buck converter through PWM generator [11].

Table 1: Rule base for DC-DC buck converter using fuzzy logic

\begin{tabular}{|c|c|c|c|c|c|c|c|}
\hline \multicolumn{1}{c|}{$\mathbf{e}$} & NB & NM & NS & $\mathbf{Z}$ & PS & PM & PB \\
\hline NB & NB & NB & NB & NB & NM & NS & Z \\
\hline NM & NB & NB & NB & NM & NS & Z & PS \\
\hline NS & NB & NB & NM & NS & Z & PS & PS \\
\hline $\mathbf{Z}$ & NB & NM & NS & Z & PS & PM & PM \\
\hline PS & NM & NS & Z & PS & PM & PB & PB \\
\hline PM & NS & Z & PS & PM & PB & PB & PB \\
\hline PB & $Z$ & PS & PM & PB & PB & PB & PB \\
\hline
\end{tabular}

The membership functions like triangular $\&$ trapezoidal are used to reduce the calculations. Fig. 4 to 6 shows the membership functions of error and change in error and output.

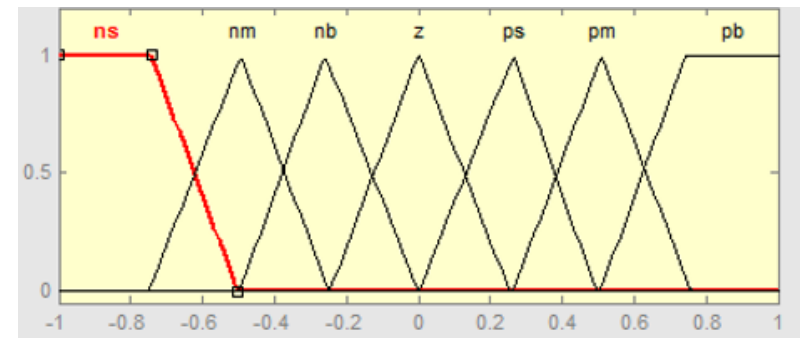

Fig.4. Input error membership function. 


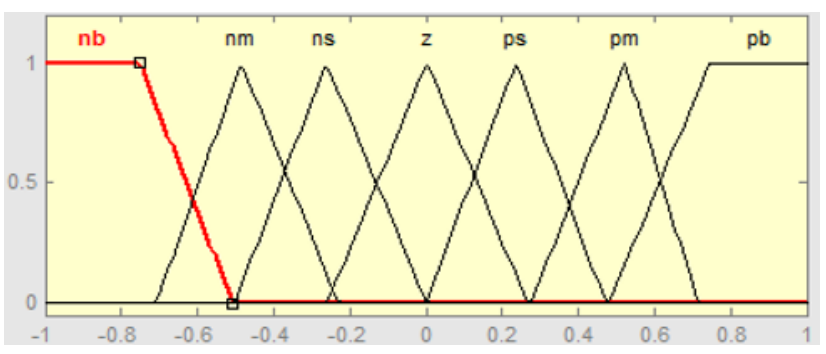

Fig.5. Membership function for Change in error

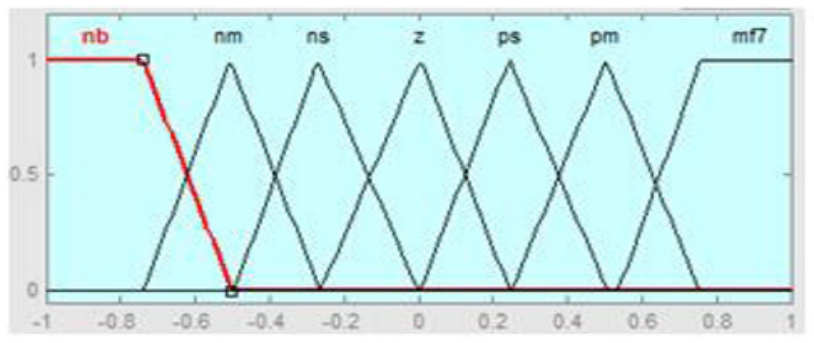

Fig.6. Change in output membership function

\subsection{Neural network:}

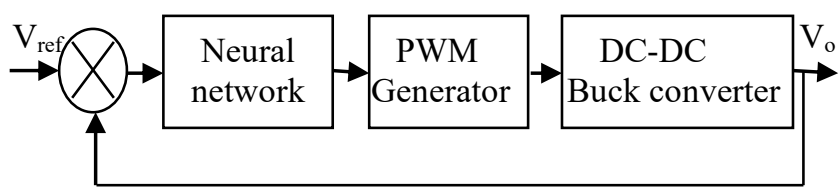

Fig.7. Block diagram of neural network $(\mathrm{NN})$ for Dc-Dc buck converter

Figure.7 shows block diagram of the neural network (NN) for buck converter. The plant identification NARMA L2 controller is used for this model. The main purpose of this model is to change the nonlinear parameters into linear parameters by deleting the non linearity's in the system. The training of the neural network is done by input from model and output from open loop model. The plant identification model for NARMA L-2 controller is shown in fig.8.

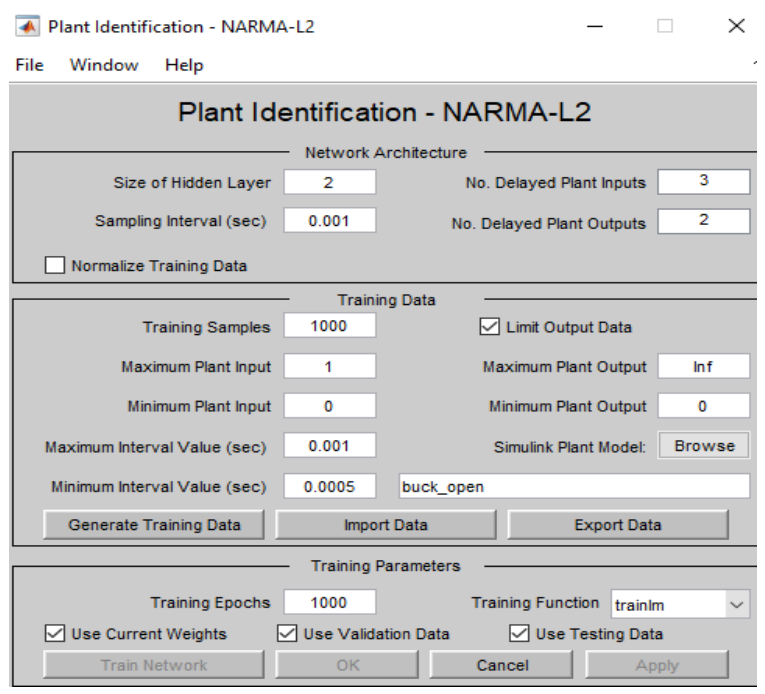

Fig.8. plant identification NARMA L2 model for training of neural network

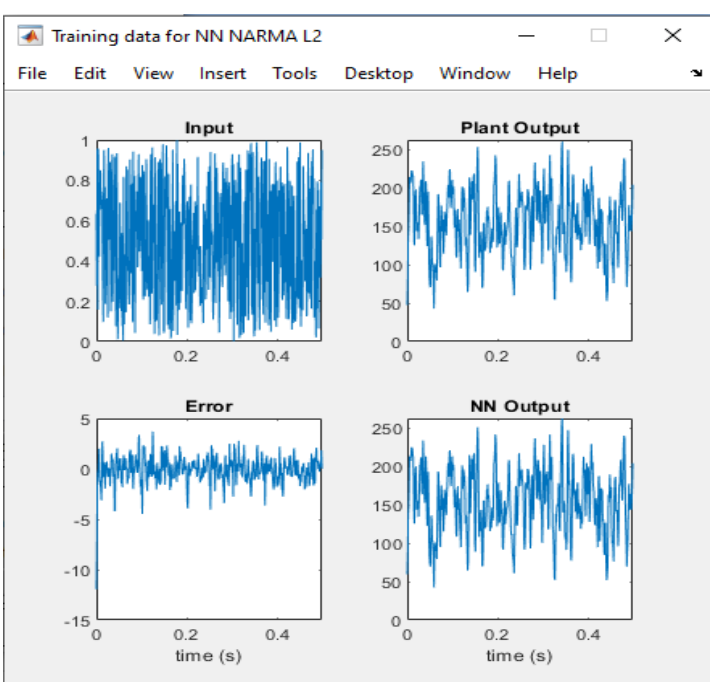

Fig.9. Training data of the neural network

\section{Simulation results}

The designed Fuzzy logic controller and NARMA L2 controller for Buck Converter is implemented in Simulink. The circuit parameters are shown in below table.

Table 2: DC-DC buck converter parameters

\begin{tabular}{|c|c|}
\hline Parameters & Values \\
\hline Output Power & $300 \mathrm{~W}$ \\
\hline Inductor & $56 \mathrm{mH}$ \\
\hline Capacitor & $13 \mathrm{uF}$ \\
\hline Input Voltage & $230 \mathrm{~V}$ \\
\hline Output Voltage & $120 \mathrm{~V}$ \\
\hline PWM Frequency & $2 \mathrm{KHz}$ \\
\hline
\end{tabular}

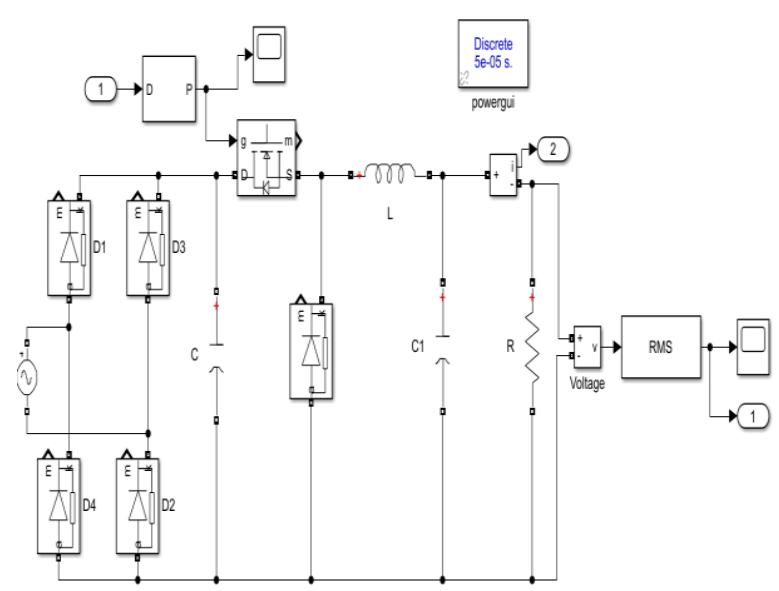

Fig.10. Simulation diagram of DC-DC Buck Converter 


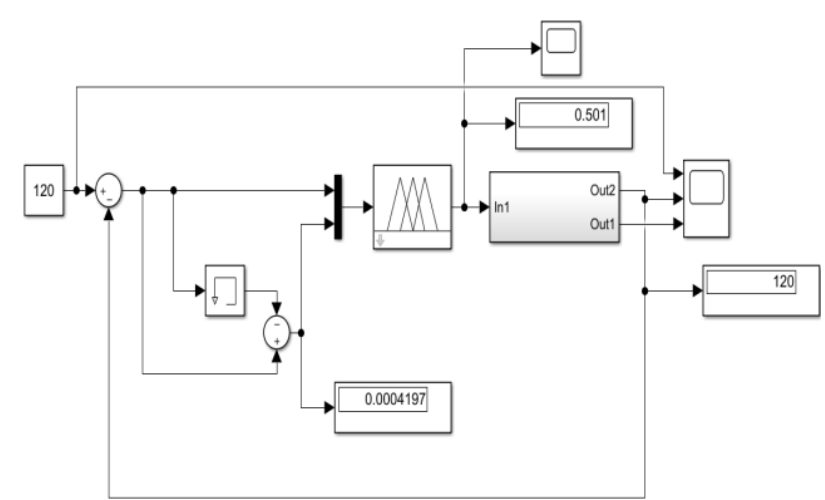

Fig.11. Proposed simulation diagram of fuzzy logic controller forDC-DC Buck Converter

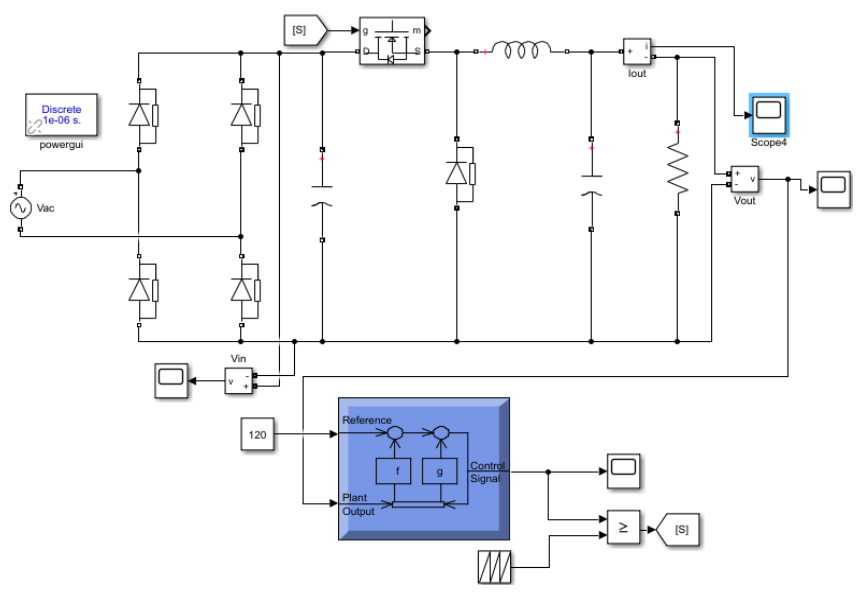

Fig.12. Proposed simulation diagram of NARMA L2 controller forDC-DC Buck Converter

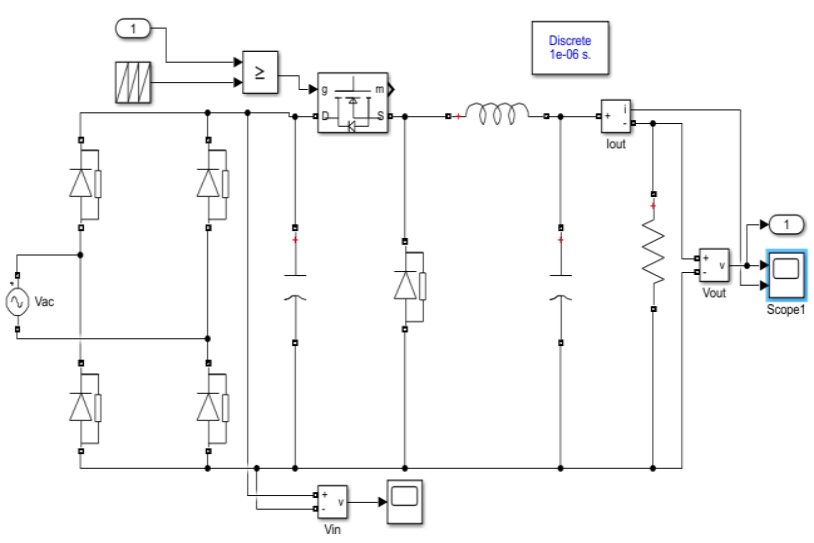

Fig.13. open loop diagram of DC-DC Buck Converter

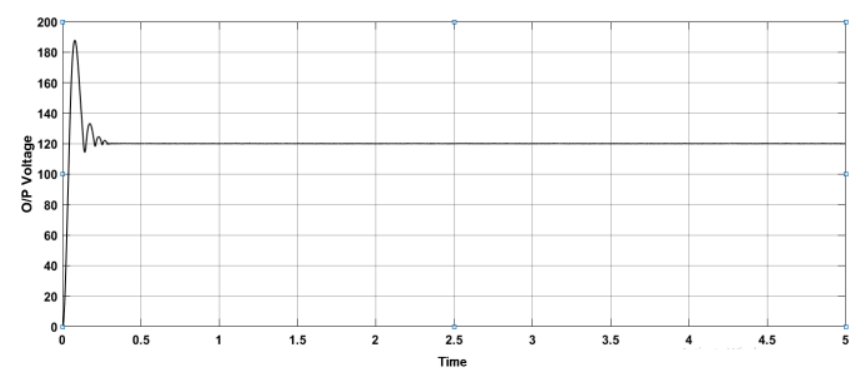

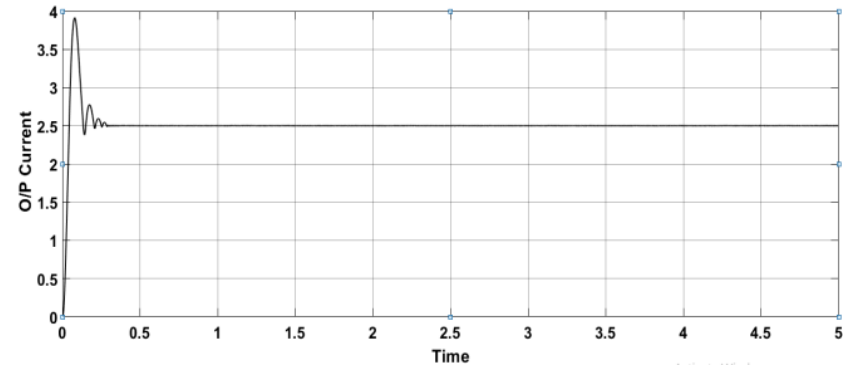

Fig.14. The waveforms output load voltage and inductor current of theDC-DC Buck Converter using Fuzzy Logic

Controller(FLC) for $120 \mathrm{~V}$
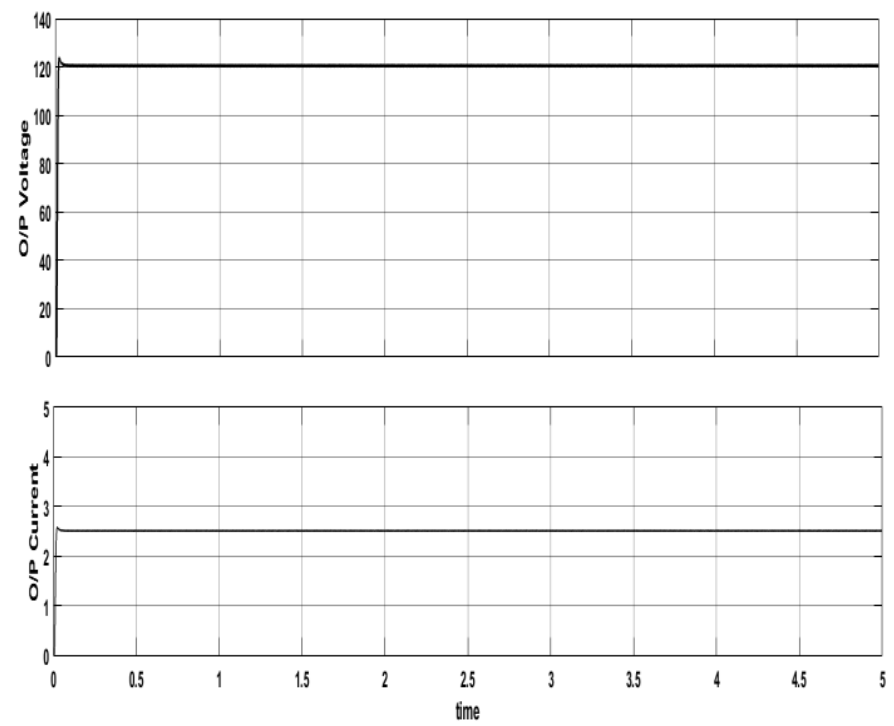

Fig.15. Waveforms output load voltage and inductor current of theDC-DC Buck Converter using NARMA L2 Controller for $120 \mathrm{~V}$

Table 3. Comparison of proposed models for different reference voltages

\begin{tabular}{|c|l|l|}
\hline $\begin{array}{c}\text { Reference } \\
\text { Voltage }\end{array}$ & $\begin{array}{l}\text { Fuzzy } \\
\text { Output }\end{array}$ & $\begin{array}{c}\text { NN } \\
\text { output }\end{array}$ \\
\hline $100 \mathrm{~V}$ & $99.3 \mathrm{~V}$ & $99.1 \mathrm{~V}$ \\
\hline $130 \mathrm{~V}$ & $129 \mathrm{~V}$ & $129.4 \mathrm{~V}$ \\
\hline $140 \mathrm{~V}$ & $139.4 \mathrm{~V}$ & $139.6 \mathrm{~V}$ \\
\hline
\end{tabular}

Table 4. Comparison of proposed models for different loads

\begin{tabular}{|l|l|l|}
\hline Load & $\begin{array}{l}\text { Fuzzy } \\
\text { Output }\end{array}$ & $\begin{array}{c}\text { NN } \\
\text { output }\end{array}$ \\
\hline $10 \Omega$ & $119.5 \mathrm{~V}$ & $119.6 \mathrm{~V}$ \\
\hline $48 \Omega$ & $120 \mathrm{~V}$ & $120.1 \mathrm{~V}$ \\
\hline $50 \Omega$ & $120.1 \mathrm{~V}$ & $120 \mathrm{~V}$ \\
\hline
\end{tabular}


Table 5. Comparison of proposed models for different input voltages

\begin{tabular}{|c|l|l|}
\hline $\begin{array}{c}\text { Input } \\
\text { Voltage }\end{array}$ & $\begin{array}{l}\text { Fuzzy } \\
\text { Output }\end{array}$ & $\begin{array}{c}\text { NN } \\
\text { output }\end{array}$ \\
\hline $150 \mathrm{~V}$ & $118.9 \mathrm{~V}$ & $119 \mathrm{~V}$ \\
\hline $180 \mathrm{~V}$ & $119.3 \mathrm{~V}$ & $119.8 \mathrm{~V}$ \\
\hline $250 \mathrm{~V}$ & $120.4 \mathrm{~V}$ & $120 \mathrm{~V}$ \\
\hline
\end{tabular}

From the above, we can conclude that when the load or input voltage parameters or the reference voltage changes the proposed model controls the duty cycle of the buck converter and gives the required output value.

Table 6. Comparison of proposed models

\begin{tabular}{|c|c|c|}
\hline & $\begin{array}{c}\text { Fuzzy logic } \\
\text { controller }\end{array}$ & $\begin{array}{c}\text { Neural } \\
\text { network }\end{array}$ \\
\hline $\begin{array}{c}\text { Settling time } \\
(\mathrm{sec})\end{array}$ & 0.28 & 0.15 \\
\hline $\begin{array}{c}\text { Maximum } \\
\text { overshoot }(\%)\end{array}$ & $57.9 \%$ & $2.58 \%$ \\
\hline
\end{tabular}

\section{Conclusion}

In this paper, the comparative analysis of fuzzy logic controller and neural network for DC-DC buck converter is studied and implemented in MATLAB/Simulink. The main purpose of this research is to understand the different smart control methods for buck converter operation. The simulations results proves both models gives the desired output but the model developed using neural network controller approach performed slightly better compared to fuzzy logic controller in terms of maximum overshoot, less steady state error and it take less time to settle down when there are non linearity's in the system. Therefore, these controllers are effectively handles the perturbations in the system thus increases the overall performance and efficiency of the buck converter.

\section{References}

[1] Muhammad H Rashid, "Power Electronics, Devices and Application", 3rd edition ,(2016) Pearson.
[2] Ms. Bhagyashri U Patil, Prof.S.R.Jagtap," Design of fuzzy based controlling system for buck converter", International Journal of Advanced Research in Computer Engineering \& Technology (IJARCET) Volume 4 Issue ( 6 June 2015).

[3] H. K. Sayed, "Modeling and Control of a Buck DCDC Converter Based on Artificial Neural Network", International Journal of Scientific \& Engineering Research, Volume 4, Issue 11, pp. 1224 - 1233, (November-2013).

[4] Chetan P Ugale, "Buck-Boost Converter using fuzzy logic for low voltage solar energy harvesting applicaion",(2017) 11th International conference on Intelligent Systems and Control(ISCO).

[5] Patil, Bhagyashri U., and Satyawan R. Jagtap."Adaptive fuzzy logic controller for buck converter", 2015 International Conference on computation of power Energy information and communication (ICCPEIC), (2015).

[6] Umair A. Shaik, "Novel product ANFIS-PID hybrid controller for buck converter" Jernoul of engineering (2018), Vol. 2018, Iss. 8,pp. 730-734.

[7] Karthik Sharma, dheeraj kumar Palwalia, "Robust controller design for DC-DC converters using fuzzy logic", $4^{\text {th }}$ International conference on Signal processing, Computing and Control, (2017), pp. 477 481.

[8] M. Lešo, J. Žilková, M. Biroš, P. Talian, "Survey of control methods for dc-dc converters", Acta Electrotechnica et Informatica, Vol. 18, No. 3, (2018), 41-46, DOI: 10.15546/aeei-2018-0024.

[9] R. Nagaraj. "Microcontroller based fuzzy logic technique for dc-dc converter", (2006) India International Conference on Power Electronics, $(12 / 2006)$

[10] K. Swathi "Design and hardware implimentation of closed loop buck converter using fuzzy logic controller ", $2^{\text {nd }}$ international conference on Electronics, Communication and Aerospace technology (2018), pp.175-180.

[11] Gergana Vacheva "Application of neural network for smart control of a buck DC/DC converter", 42nd International Spring Seminar on Electronics Technology (ISSE), (2019).

[12] Saon Maity, Soham Ghosh, Rounak Pal, "Performance analysis of fuzzy logic controlled DCDC converters", International conference on Communication and signal processing, (2019), pp.0165-0171. 